\title{
Breast cancer risk prediction in women aged 35-50 years: impact of including sex hormone concentrations in the Gail model
}

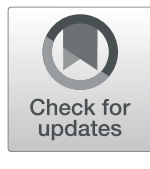

Tess V. Clendenen ${ }^{1 \dagger}$, Wenzhen Ge ${ }^{1 \dagger}$, Karen L. Koenig ${ }^{1}$, Yelena Afanasyeva ${ }^{1}$, Claudia Agnoli', Louise A. Brinton ${ }^{5}$, Farbod Darvishian ${ }^{2,3}$, Joanne F. Dorgan ${ }^{6}$, A. Heather Eliassen ${ }^{7}$, Roni T. Falk ${ }^{5}$, Göran Hallmans ${ }^{9}$, Susan E. Hankinson ${ }^{7,8}$, Judith Hoffman-Bolton ${ }^{10}$, Timothy J. Key ${ }^{12}$, Vittorio Krogh ${ }^{4}$, Hazel B. Nichols ${ }^{13}$, Dale P. Sandler ${ }^{14}$, Minouk J. Schoemaker ${ }^{15,16}$, Patrick M. Sluss ${ }^{17}$, Malin Sund ${ }^{18}$, Anthony J. Swerdlow ${ }^{15}$, Kala Visvanathan ${ }^{10,11}$, Anne Zeleniuch-Jacquotte ${ }^{1,3+}$ and Mengling Liu ${ }^{1,3^{*}+}$

\begin{abstract}
Background: Models that accurately predict risk of breast cancer are needed to help younger women make decisions about when to begin screening. Premenopausal concentrations of circulating anti-Müllerian hormone $(\mathrm{AMH})$, a biomarker of ovarian reserve, and testosterone have been positively associated with breast cancer risk in prospective studies. We assessed whether adding $\mathrm{AMH}$ and/or testosterone to the Gail model improves its prediction performance for women aged 35-50.
\end{abstract}

Methods: In a nested case-control study including ten prospective cohorts (1762 invasive cases/1890 matched controls) with pre-diagnostic serum/plasma samples, we estimated relative risks (RR) for the biomarkers and Gail risk factors using conditional logistic regression and random-effects meta-analysis. Absolute risk models were developed using these RR estimates, attributable risk fractions calculated using the distributions of the risk factors in the cases from the consortium, and population-based incidence and mortality rates. The area under the receiver operating characteristic curve (AUC) was used to compare the discriminatory accuracy of the models with and without biomarkers.

Results: The AUC for invasive breast cancer including only the Gail risk factor variables was 55.3 ( $95 \%$ Cl 53.4, 57.1). The AUC increased moderately with the addition of AMH (AUC 57.6, 95\% Cl 55.7, 59.5), testosterone (AUC 56.2, 95\% Cl 54.4, 58.1), or both (AUC 58.1, 95\% Cl 56.2, 59.9). The largest AUC improvement (4.0) was among women without a family history of breast cancer.

Conclusions: $\mathrm{AMH}$ and testosterone moderately increase the discriminatory accuracy of the Gail model among women aged 35-50. We observed the largest AUC increase for women without a family history of breast cancer, the group that would benefit most from improved risk prediction because early screening is already recommended for women with a family history.

Keywords: Breast cancer risk prediction, Anti-Müllerian hormone, Testosterone, Gail model

\footnotetext{
* Correspondence: mengling.liu@nyumc.org

Wenzhen Ge and Tess V. Clendenen are co-first authors.

Mengling Liu and Anne Zeleniuch-Jacquotte are co-last authors.

'Department of Population Health, New York University School of Medicine,

650 First Avenue, New York, NY 10016, USA

${ }^{3}$ Perlmutter Cancer Center, New York University School of Medicine, New

York, NY, USA

Full list of author information is available at the end of the article
}

(C) The Author(s). 2019 Open Access This article is distributed under the terms of the Creative Commons Attribution 4.0 International License (http://creativecommons.org/licenses/by/4.0/), which permits unrestricted use, distribution, and reproduction in any medium, provided you give appropriate credit to the original author(s) and the source, provide a link to the Creative Commons license, and indicate if changes were made. The Creative Commons Public Domain Dedication waiver (http://creativecommons.org/publicdomain/zero/1.0/) applies to the data made available in this article, unless otherwise stated. 


\section{Background}

Breast cancer risk prediction models can help women and their health providers make decisions about screening and chemoprevention. While women aged 50 are uniformly included in mammographic screening recommendations, the guidelines regarding at what age to start screening are inconsistent, varying from age 40 to 50 , particularly for women without a family history of breast cancer (https://www.uspreventiveservicestaskforce.org/ Page/Document/UpdateSummaryFinal/breast-cancer-scr eening1 [1-7]). Improvements in individualized risk assessment would therefore be particularly valuable for women younger than 50 to decide when to start mammographic screening. A risk prediction model with high accuracy could also help women decide whether to take tamoxifen for breast cancer prevention. Younger women are more likely to benefit from tamoxifen than older women because they have lower risks of tamoxifen-related adverse events [8-13]. Nonetheless, an accurate estimate of risk of breast cancer is critical in calculating the benefit-risk index for these women.

The Gail model 2 [14] is the most widely studied breast cancer risk prediction model for women without a strong family history of breast cancer or an inherited mutation associated with high susceptibility. The breast cancer risk factors in the model are age, age at menarche, age at first live birth, number of previous breast biopsies, history of atypical hyperplasia, and first-degree family history of breast cancer [14]. The Gail model 2 was initially developed using data from white women, and race/ethnicity-specific adaptations of the model were subsequently developed. The model was implemented in the National Cancer Institute's Breast Cancer Risk Assessment Tool (BCRAT) which is available online. The model has been validated in studies in the USA and several Western European countries, including studies of younger women [15-23]. It has been shown in most studies to be well calibrated $[14,15,23]$, i.e., it predicts fairly accurately the number of women who will develop breast cancer overall and in subgroups defined by risk factors. However, the model has limited discriminatory accuracy, i.e., it does not separate well women who subsequently develop cancer from those who do not [15].

We recently showed that the premenopausal circulating concentration of anti-Müllerian hormone (AMH), a marker of ovarian reserve, is associated with risk of breast cancer [24]. Circulating testosterone concentration, measured before [25-30] or after menopause [31-38], has also been consistently associated with breast cancer risk. $\mathrm{AMH}$ and testosterone are fairly stable during the menstrual cycle and temporal reliability studies have shown that a single measurement of AMH or testosterone can be used to rank premenopausal women with regard to their average hormone level over a several-year period with reasonable accuracy [25, 34, 39-42]. They are also relatively inexpensive to measure. Thus, these two hormones are good candidate biomarkers for inclusion in breast cancer risk prediction models for younger women, who have large fluctuations in other hormone-related biomarkers during the menstrual cycle.

The objective of this study was to evaluate whether adding circulating $\mathrm{AMH}$ and/or testosterone measurements to the Gail model improves its discriminatory accuracy among women aged 35-50.

\section{Methods}

\section{Study subjects}

Participants in a nested case-control study in a consortium of ten prospective cohorts from the USA, UK, Italy, and Sweden [24] were included in this study. The parent cohorts were the Generations Study (BGS); CLUE II; Columbia, MO Serum Bank (CSB); Guernsey Cohort; New York University Women's Health Study (NYUWHS); Nurses' Health Studies (NHS) I and II; Northern Sweden Mammary Screening Cohort (NSMSC); Hormones and Diet in the Etiology of Breast Cancer (ORDET); and the Sister Study (Sister). A brief description of the cohorts can be found in Ge et al. [24]. Each cohort was approved by its institutional review board, and informed consent was obtained from each participant.

Incident breast cancer cases were ascertained by each cohort through self-report on follow-up questionnaires and/or linkages with local, regional, or national cancer registries. All cases of incident invasive breast cancer diagnosed among women who were $35-50$ at the time of blood donation were included except in the NHS cohorts, which further limited case selection to women who were premenopausal and between the ages of 3550 at diagnosis. Controls were selected within each cohort using incidence density sampling. One control was selected for each case (except for the Sister Study, which matched 1:2). Matching variables included age and date of blood donation, and race/ethnicity [24]. Many of the cohorts matched on additional variables, for example, phase or day of menstrual cycle and technical sample characteristics, such as time between collection and processing. Women who were ever users of hormone therapy (HT) or current users of oral contraceptives (OCs) were excluded.

\section{Laboratory measurements}

$\mathrm{AMH}$ was measured in serum or plasma samples from women who were premenopausal at the time of blood donation using the picoAMH assay (ANSH laboratories) [24]. Women who had AMH concentrations below the lowest detectable value (LDV) $(<10 \%$ of samples for eight cohorts and $<20 \%$ for the remaining two cohorts) 
were classified into the lowest quartile for analyses (see "Statistical methods"). Because it has previously been shown that postmenopausal women have AMH concentrations below the LDV [43, 44], we did not measure AMH in postmenopausal women (23 cases and 40 controls) but also classified them into the lowest quartile.

Total testosterone was measured for all subjects in CLUE II, NHS, and NSMSC and for the matched sets for which it was not measured previously for the other cohorts. Measurements were done in the Immunochemical Core Laboratory of the Mayo Clinic by liquid chromatography-tandem mass spectrometry (LC-MS/MS). Assay coefficients of variation (CVs) were calculated using blinded quality control samples. For $\mathrm{AMH}$, the mean intra-batch $\mathrm{CV}$ was $5.1 \%$ and the inter-batch $\mathrm{CV}$ was 21.4\%. For testosterone, all intra- and inter-batch CVs were $\leq 10.6 \%$. Previous testosterone measurements were performed as described in [25, 26, 29, 45-48].

\section{Statistical methods \\ Relative risk estimation}

We estimated cohort-specific relative risks (RRs) associated with the breast cancer risk factors included in the Gail model and with each of the biomarkers (testosterone and $\mathrm{AMH}$ ) using conditional logistic regression (odds ratio estimates are referred to throughout as relative risks (RRs), by convention). Cohort-specific RRs were combined to obtain consortium-wide RR estimates using the random-effects meta-analytic method. $I^{2}$ and Q-tests were used to test for heterogeneity across cohorts.

We used the same coding as the BCRAT for age at menarche $(<12$ years, 12 to 13 , or $\geq 14)$ and age at first live birth $(<20,20$ to 24,25 to 29 /nulliparous, or $\geq 30$ years) [14]. Family history of breast cancer was coded using a three-category variable $(0 / 1 />1$ affected relative(s)). For cohorts that collected family history as a yes/no variable, women who responded yes were included in the intermediate category ( 1 affected relative). History of breast biopsy was coded as yes/no. We did not include an interaction between breast biopsy and age $(<50 / \geq 50$ years) because this study was restricted to younger women $(\leq 50)$. The interaction term between age at first birth and number of affected relatives was not statistically significant for any cohort and thus not included in the model. To be consistent with BCRAT, which imputes missing data to the lowest risk category, we imputed missing data as follows: age at menarche: $\geq$ 14 for 35 cases $(1.5 \%)$ and 49 controls (1.9\%); age at first live birth: < 20 for 5 cases $(0.2 \%)$ and $7(0.3 \%)$ controls; and number of breast biopsies: 0 for 42 cases $(1.8 \%)$ and 40 controls (1.6\%). Data on history of atypical hyperplasia were not available from any of the cohorts and this variable was set to the lowest risk category as is the case when "unknown" is entered in the BCRAT. Because we could not exclude the possibility that cohort differences in the $\mathrm{AMH}$ and testosterone concentration distributions were related to collection/handling/storage of samples [24], biomarkers were categorized into quartiles using cohort-specific cutpoints and modeled as ordered categorical variables.

\section{Absolute risk estimation}

We used the method described by Gail et al. [22, 49] to estimate the 5-year absolute breast cancer risk for each participant. We used consortium-wide estimates of RRs for the Gail variables and biomarkers (calculated as described above), consortium-based estimates of attributable risk fractions, and population-based breast cancer incidence and mortality rates. Attributable risk fractions were estimated using consortium-wide RR estimates and distributions of the Gail variables and biomarkers in the cases (excluding the Sister Study because all women in this study had a family history of breast cancer) [49]. Breast cancer incidence and competing mortality (i.e., non-breast cancer mortality) rates were obtained from the countries of the participating cohorts (US, UK, Italy, and Sweden) for the relevant 5-year age categories (35-39, 40-44, 45-49) and calendar years of blood collection (Additional file 1: Table S1).

For comparison, we also calculated the 5-year absolute risks of developing breast cancer using the BCRAT SAS macro (available at: https://dceg.cancer.gov/tools/risk-assessment/bcrasasmacro), which uses US populationbased RR estimates $[8,14,15,22]$. We refer to results using these calculations as "BCRAT" (to distinguish them from results based on RRs estimated from our dataset, called "Gail model").

\section{Assessment of discriminatory accuracy}

We estimated the area under the receiver operating characteristic curve (AUC) based on the 5-year absolute risk estimates from the BCRAT, the Gail model, and the Gail model with addition of AMH and/or testosterone. Summary AUCs were estimated from the cohort-specific AUCs using random-effects meta-analytic methods. AUCs were also estimated within subgroups, i.e., by age, estrogen receptor (ER) status of the tumor, and Gail risk score $(<1 \% / \geq 1 \%)$, and for women without a family history of breast cancer. AUCs are expressed throughout as percentages $($ AUC $\times 100)$ for ease of interpretation. Finally, we assessed reclassification of 5-year absolute risks upon addition of biomarkers.

\section{Results}

Descriptive characteristics of the cases and controls are shown in Table 1 . By design, women were between the ages of $35-50$ at blood donation. About $40 \%$ of cases 
Table 1 Descriptive characteristics of invasive breast cancer cases and matched controls

\begin{tabular}{lll}
\hline & Cases $(n=1762)$ & Controls $(n=1890)$ \\
\hline Cohort, $n$ & & \\
BGS & 230 & 230 \\
CLUE II & 87 & 87 \\
CSB & 69 & 69 \\
Guernsey & 124 & 124 \\
NHS & 93 & 93 \\
NHS II & 248 & 250 \\
NSMSC & 31 & 31 \\
NYUWHS & 493 & 496 \\
ORDET & 214 & 224 \\
Sister & 173 & 286
\end{tabular}

Age at blood donation, years, $n(\%)$

$\begin{array}{lll}35-40 & 472(26.8) & 487(25.8) \\ 41-45 & 708(40.2) & 752(39.8) \\ 46-50^{\mathrm{a}} & 582(33.0) & 651(34.5)\end{array}$

Race/ethnicity, $n$ (\%)

$\begin{array}{lll}\text { White } & 1587(90.1) & 1696(89.7) \\ \text { Black/African American } & 76(4.3) & 73(3.9) \\ \text { Other or missing } & 99(5.6) & 121(6.4)\end{array}$

Age at diagnosis, years, $n(\%)$

$\begin{array}{ll}35-45 & 287(16.3) \\ 46-50 & 579(32.9) \\ 51-55 & 436(24.7) \\ 56-60 & 235(13.3) \\ 61-65 & 141(8.0) \\ >65 & 84(4.8)\end{array}$

Lag time between blood donation and diagnosis, years, $n(\%)$

$\begin{array}{ll}0-2 & 274(15.6) \\ 3-5 & 420(23.8) \\ 6-10 & 443(25.1) \\ 11-15 & 286(16.2) \\ 16-20 & 201(11.4) \\ >20 & 138(7.8)\end{array}$

Age at menarche, years, $n(\%)$

$\begin{array}{lll}<12 & 376(21.3) & 411(21.7) \\ 12-13 & 976(55.4) & 1012(53.5) \\ \geq 14 \text { or missing }^{b} & 410(23.3) & 467(24.7)\end{array}$

Age at first live birth, years, $n(\%)$

$\begin{array}{lll}<20 \text { or missing }^{b} & 114(6.5) & 143(7.6) \\ 20-24 & 457(25.9) & 521(27.6) \\ 25-29^{c} & 473(26.8) & 511(27.1) \\ \geq 30 & 304(17.3) & 307(16.2) \\ \text { Nulliparous } & 414(23.5) & 408(21.5)\end{array}$

Table 1 Descriptive characteristics of invasive breast cancer cases and matched controls (Continued)

\begin{tabular}{lll}
\hline & Cases $(n=1762)$ & Controls $(n$ \\
\hline $\begin{array}{lll}\text { Number of benign breast biopsies, } n(\%) \\
0 \text { or missing }\end{array}$ & $1339(76.0)$ & $1559(82.5)$ \\
$\geq 1$ & $423(24.0)$ & $331(17.5)$ \\
0 & $1311(74.4)$ & $1415(74.9)$ \\
$1^{d}$ & $382(21.7)$ & $412(21.8)$ \\
$>1^{d}$ & $69(3.9)$ & $63(3.3)$
\end{tabular}

BMI, $\mathrm{kg} / \mathrm{m}^{2}, n(\%)$

$\begin{array}{lll}<25 & 1097(59.9) & 1124(62.6) \\ 25-29 & 420(24.8) & 465(24.0) \\ \geq 30 & 234(15.4) & 289(13.4) \\ \text { Missing } & 11 & 12\end{array}$

AMH cohort-specific quartiles, $n(\%)$

$\begin{array}{lll}\text { Q1 } & 365(20.7) & 480(25.4) \\ \text { Q2 } & 444(25.1) & 468(24.8) \\ \text { Q3 } & 453(25.7) & 468(24.8) \\ \text { Q4 } & 500(28.4) & 474(25.1)\end{array}$

Testosterone cohort-specific quartiles, $n(\%)$

$\begin{array}{lll}\text { Q1 } & 423(24.0) & 511(27.0) \\ \text { Q2 } & 414(23.5) & 464(24.6) \\ \text { Q3 } & 452(25.7) & 460(24.3) \\ \text { Q4 } & 473(26.8) & 455(24.1)\end{array}$

BCRAT 5-year risk score (\%), $n(\%)^{\mathrm{e}}$

$\begin{array}{lll}<0.6 \% & 296(16.8) & 332(17.6) \\ 0.6-0.99 \% & 679(38.5) & 765(40.5) \\ 1-1.66 \% & 525(29.8) & 517(27.3) \\ 1.67-1.99 \% & 110(6.2) & 130(6.9) \\ 2-2.99 \% & 115(6.5) & 115(6.1) \\ \geq 3 \% & 37(2.1) & 31(1.6)\end{array}$

ER status, $n(\%)$

ER-positive $\quad 1139(79.8)$

ER-negative $\quad 289(20.2)$

Unknown 334

Note: Cases and controls were matched 1:1 for all cohorts except for Sister Study which matched 1:2

${ }^{a}$ All cases had age at blood donation $\leq 50$, though for 24 sets, matched controls ages were $\leq 51.2$ years at blood donation

${ }^{\mathrm{b}}$ To be consistent with BCRAT, which imputes missing data to the lowest risk category, we imputed missing data as follows: age at menarche: $\geq 14$ for 35 cases (1.5\%) and 49 controls (1.9\%); age at first live birth: $<20$ for 5 cases $(0.2 \%)$ and $7(0.3 \%)$ controls; number of breast biopsies: 0 for 42 cases (1.8\%) and 40 controls (1.6\%) 'As done in BCRAT, nulliparous and women who were $25-29$ at first birth were combined in all models

${ }^{\mathrm{d}}$ The number of first-degree family members with breast cancer was coded as 0,1 , or $>1$ affected relatives. For cohorts that collected family history as a no/yes variable, "yes" answers were assigned to the intermediate category ( 1 affected relative) ${ }^{\text {e}}$ Calculated using the following variables: race, age at menarche, age at first live birth, number of breast biopsies, and number of first-degree family members with breast cancer, history of atypical hyperplasia was missing for all cohorts and set to "no." Gail model 2 rates and parameters were used as described in [14] 
donated blood samples in the 5 years preceding breast cancer diagnosis. Consistent with known breast cancer risk factor associations, cases were more likely than controls to have had a breast biopsy, to have a family history of breast cancer, and to be nulliparous or have had their first live birth after age 30. The vast majority of women had low to average BCRAT 5-year risk scores (over half of the women had a risk $<1 \%$ ), as expected in a study of younger women.

Table 2 shows the RR estimates for invasive breast cancer associated with Gail model risk factors and biomarkers. The RRs for the Gail model variables did not change appreciably with the addition of biomarkers to the model. When individually added to the Gail model, $\mathrm{AMH}$ was associated with a $55 \%$ increase in risk and testosterone with a $27 \%$ increase in risk for the 4 th vs. 1 st quartiles; when added together, AMH was associated with a $53 \%$, and testosterone with a $22 \%$, increase. Table 2 also shows the attributable risk fraction estimates for each unit increase in risk factor or biomarker. For Gail model variables, the risk attributable to age at menarche was low $(<1 \%)$, while attributable risks were higher for family history of breast cancer (7\%), history of breast biopsy (8\%), and age at first pregnancy (18\%). The attributable risk for a one-quartile increase in AMH was $19 \%$ and for testosterone $9 \%$. In a sensitivity analysis restricted to the five US cohorts included in our study, the attributable risks calculated using US population risk factor distributions were similar to estimates based on risk factor distributions in the cases (data not shown) [22, 49-51]. Cohort-specific RR estimates for invasive breast cancer from the model including both biomarkers

Table 2 Relative risks calculated using random-effects meta-analysis and attributable risk fractions

\begin{tabular}{|c|c|c|c|c|c|}
\hline \multirow[t]{2}{*}{ Risk factor } & \multicolumn{4}{|l|}{ RR estimates } & \multirow{2}{*}{$\begin{array}{l}\text { Attributable risk (\%) for } \\
\text { Gail+ AMH + testosterone } \\
\text { model }^{b}\end{array}$} \\
\hline & $\overline{\text { Gail }}$ & Gail + AMH & Gail + testosterone & Gail + AMH + testosterone & \\
\hline \multicolumn{5}{|l|}{ Age at menarche, years } & $0.67 \%$ \\
\hline$<12$ & $1.00(0.90,1.11)$ & $1.02(0.91,1.13)$ & $1.00(0.90,1.11)$ & $1.01(0.91,1.12)$ & \\
\hline $12-13$ & $1.00(0.90,1.11)$ & $1.01(0.91,1.12)$ & $1.00(0.90,1.11)$ & $1.01(0.91,1.12)$ & \\
\hline$\geq 14$ & 1.0 (ref) & 1.0 (ref) & 1.0 (ref) & 1.0 (ref) & \\
\hline \multicolumn{5}{|l|}{ Age at first live birth, years } & $18.47 \%$ \\
\hline$<20$ & 1.0 (ref) & 1.0 (ref) & 1.0 (ref) & 1.0 (ref) & \\
\hline $20-24$ & $1.11(1.00,1.24)$ & $1.12(1.00,1.25)$ & $1.12(1.00,1.26)$ & $1.12(1.00,1.26)$ & \\
\hline 25-29 or nulliparous & $1.24(1.11,1.38)$ & $1.25(1.12,1.39)$ & $1.26(1.12,1.41)$ & $1.26(1.13,1.42)$ & \\
\hline$\geq 30$ & $1.38(1.23,1.54)$ & $1.40(1.25,1.56)$ & $1.41(1.26,1.58)$ & $1.42(1.27,1.60)$ & \\
\hline \multicolumn{5}{|c|}{ Number of benign breast biopsies } & $8.13 \%$ \\
\hline 0 & 1.0 (ref) & 1.0 (ref) & 1.0 (ref) & 1.0 (ref) & \\
\hline$\geq 1$ & $1.58(1.33,1.88)$ & $1.55(1.31,1.85)$ & $1.59(1.34,1.89)$ & $1.56(1.31,1.86)$ & \\
\hline \multicolumn{5}{|c|}{ Number of first-degree family members with breast cancer ${ }^{a}$} & $6.56 \%$ \\
\hline 0 & 1.0 (ref) & 1.0 (ref) & 1.0 (ref) & 1.0 (ref) & \\
\hline 1 & $1.58(1.32,1.89)$ & $1.57(1.31,1.88)$ & $1.57(1.30,1.88)$ & $1.56(1.30,1.87)$ & \\
\hline$>1$ & $2.49(2.08,2.99)$ & $2.47(2.06,2.96)$ & $2.45(2.04,2.94)$ & $2.43(2.03,2.92)$ & \\
\hline \multicolumn{5}{|l|}{$\mathrm{AMH}$} & $19.38 \%$ \\
\hline Q1 & - & 1.0 (ref) & - & 1.0 (ref) & \\
\hline Q2 & - & $1.16(1.04,1.29)$ & - & $1.15(1.03,1.28)$ & \\
\hline Q3 & - & $1.34(1.20,1.49)$ & - & $1.33(1.19,1.48)$ & \\
\hline Q4 & - & $1.55(1.39,1.73)$ & - & $1.53(1.37,1.70)$ & \\
\hline \multicolumn{5}{|l|}{ Testosterone } & $9.48 \%$ \\
\hline Q1 & - & - & 1.0 (ref) & 1.0 (ref) & \\
\hline Q2 & - & - & $1.08(1.02,1.15)$ & $1.07(1.00,1.14)$ & \\
\hline Q3 & - & - & $1.17(1.10,1.25)$ & $1.14(1.07,1.22)$ & \\
\hline Q4 & - & - & $1.27(1.19,1.35)$ & $1.22(1.15,1.30)$ & \\
\hline
\end{tabular}

${ }^{\mathrm{a}}$ The number of first-degree family members with breast cancer was coded as either 0,1 , or $>1$ affected relatives. For cohorts that collected family history as a no/yes variable, "yes" answers were assigned to the intermediate category ( 1 affected relative)

${ }^{b}$ We used the method described in Bruzzi et al. [49] to estimate attributable risk for a one-category increase (or decrease for age at menarche) in the risk factor. The Sister study was excluded from attributable risk estimation because all participants had a family history of breast cancer 
are shown in Additional file 1: Figure S1. Tests for heterogeneity by cohort were not statistically significant. Removing one cohort at a time from the analysis did not change the RRs appreciably (data not shown).

Figure 1 and Table 3 show the AUCs based on BCRAT, the Gail model, and the Gail model with biomarkers. The summary AUC for invasive breast cancer using the BCRAT was 55.0 (95\% CI 53.1, 56.8). The AUC in our implementation of the Gail model was very similar (AUC 55.3, 95\% CI 53.4, 57.1). The AUC increased with the addition of AMH (AUC 57.6, 95\% CI 55.7, 59.5), testosterone (AUC 56.2, 95\% CI 54.4, 58.1), and both $\mathrm{AMH}$ and testosterone (AUC 58.1, 95\% CI 56.2, 59.9). The percent increase relative to the Gail model was statistically significant for the model including $\mathrm{AMH}(4.2 \%, p=0.007)$ and the model including both AMH and testosterone (5.1\%, $p=0.001)$, but not testosterone alone $(1.6 \%, p=0.086)$. AUCs were similar when

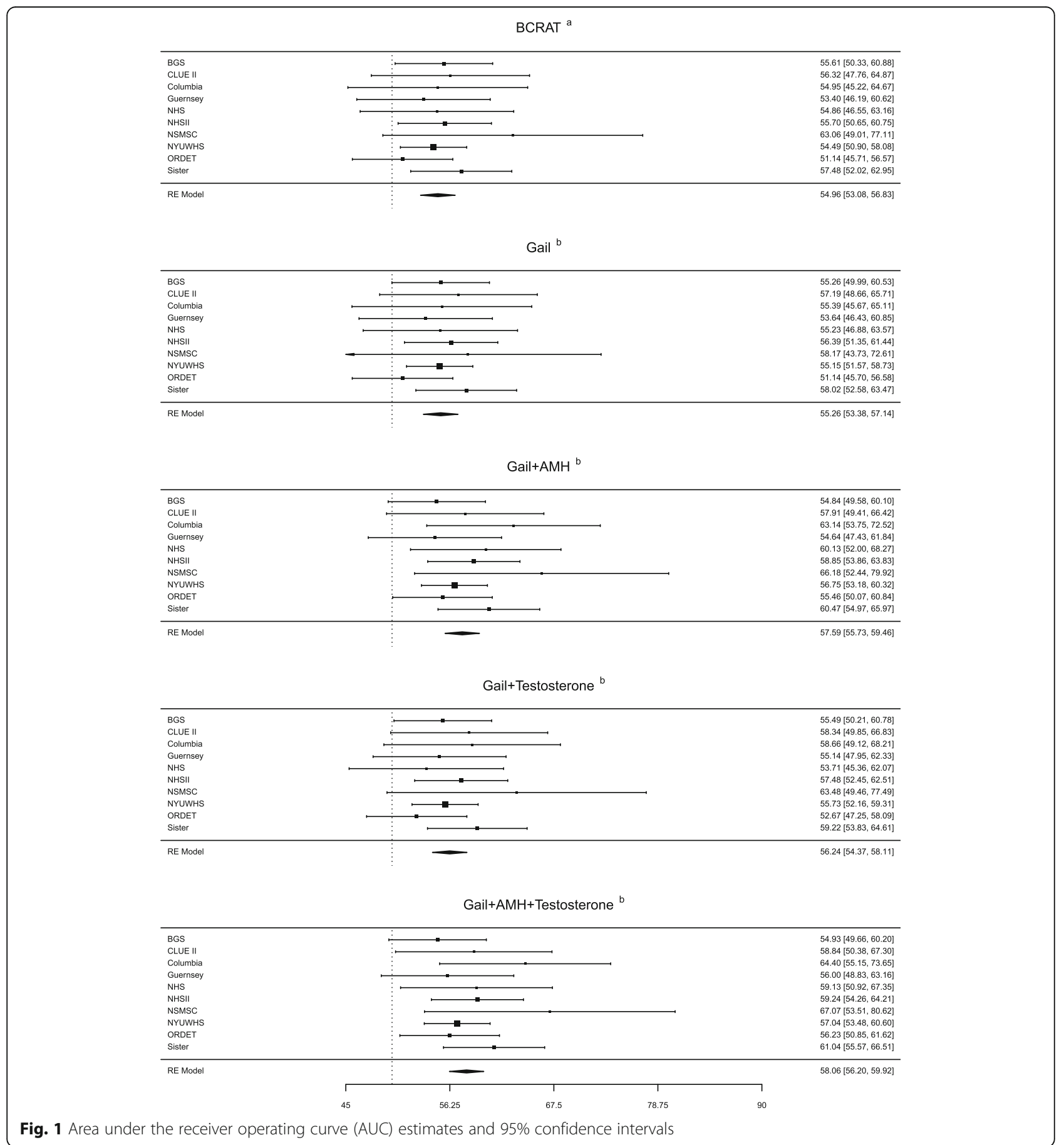


Table 3 AUCs by subgroups

\begin{tabular}{|c|c|c|c|c|c|}
\hline & $\mathrm{BCRAT}^{\mathrm{a}}$ & Gail $^{b}$ & Gail + AMH ${ }^{\mathrm{b}}$ & Gail + testosterone ${ }^{b}$ & Gail + AMH + testosterone ${ }^{\mathrm{b}}$ \\
\hline Total AUC & $55.0(53.1,56.8)$ & $55.3(53.4,57.1)$ & $57.6(55.7,59.5)$ & $56.2(54.4,58.1)$ & $58.1(56.2,59.9)$ \\
\hline \multicolumn{6}{|c|}{ Age at blood donation, years } \\
\hline$\leq 40$ & $55.9(52.3,59.6)$ & $56.2(52.5,59.8)$ & $57.5(53.8,61.1)$ & $57.3(53.7,61.0)$ & $58.1(54.4,61.8)$ \\
\hline $41-45$ & $55.2(52.2,58.2)$ & $54.9(51.9,57.9)$ & $56.3(53.3,59.2)$ & $56.0(53.0,58.9)$ & $56.6(53.7,59.6)$ \\
\hline$>45$ & $58.6(55.4,61.9)$ & $58.6(55.3,61.9)$ & $60.6(57.4,63.8)$ & $60.9(57.7,64.1)$ & $62.1(58.9,65.3)$ \\
\hline \multicolumn{6}{|c|}{ Gail 5-year risk score, \% } \\
\hline$<1^{c}$ & $53.2(50.2,55.2)$ & $52.9(50.4,55.4)$ & $54.7(52.2,57.2)$ & $54.3(51.8,56.8)$ & $55.9(53.4,58.3)$ \\
\hline$\geq 1^{c}$ & $56.6(53.7,59.5)$ & $58.2(55.3,61.0)$ & $59.1(56.3,62.0)$ & $57.4(54.3,60.5)$ & $59.2(56.3,62.1)$ \\
\hline \multicolumn{6}{|c|}{ Estrogen receptor status } \\
\hline ER-positive & $56.1(53.8,58.4)$ & $56.4(54.1,58.8)$ & $58.9(56.2,61.6)$ & $57.2(54.9,59.5)$ & $59.2(56.3,62.0)$ \\
\hline ER-negative & $55.8(51.1,60.5)$ & $56.8(52.1,61.5)$ & $58.0(53.3,62.7)$ & $57.1(52.4,61.8)$ & $57.1(52.3,61.8)$ \\
\hline \multicolumn{6}{|c|}{ Number of first-degree family members with breast cancer, $n(\%)$} \\
\hline 0 & $52.2(50.0,54.3)$ & $52.8(50.6,55.0)$ & $55.6(52.9,58.3)$ & $54.6(52.4,56.8)$ & $56.8(54.6,58.9)$ \\
\hline$\geq 1$ & $55.9(52.1,59.6)$ & $55.0(51.3,58.7)$ & $57.2(53.4,60.9)$ & $56.4(52.7,60.1)$ & $57.2(52.0,62.4)$ \\
\hline
\end{tabular}

${ }^{a}$ Estimates from the model as implemented in BCRAT and using BCRAT regression coefficients

${ }^{\mathrm{b}}$ Model including Gail model variables and biomarker(s) and using regression coefficients in Table 2

${ }^{\mathrm{C}}$ Median 5-year absolute risk was approximately $1 \%$

both in situ and invasive cases were considered together (Additional file 1: Figure S4).

Table 3 also shows AUCs in subgroups. Small improvements in AUCs with the addition of both biomarkers to the Gail model were observed in each age-at-blood-donation subgroup, with the largest increase (3.5, a relative increase of $6.0 \%$ ) for women ages 45-50, for whom the Gail model also had the highest AUC (58.6). AUC improvements for women with a 5 -year risk lower than $1 \%$ were greater (3.0, a relative increase of 5.7\%) than those for women with risk of at least $1 \%$ (1.0, a relative increase of $1.7 \%)$. AUC improvement was larger for ER-positive tumors (2.8, a relative increase of 5.0\%) than ER-negative tumors (0.3, a relative increase of $0.5 \%)$. We also found that the AUC increased (4.0, a relative increase of $7.6 \%$ ) with the addition of biomarkers for the subgroup of women without a family history of breast cancer, but less so for women with a family history (2.2, a relative increase of $4.4 \%$ ).

Figure 2 shows the histograms displaying absolute risk estimates of cases and controls for the Gail model with and without testosterone and AMH. Though there was substantial overlap between the distributions in cases and controls, the distribution was skewed to the right for cases. Adding the biomarkers resulted in a slight shift of the distribution to the right for cases $(9.3 \%$ had risk estimates move from below to above $1 \%$, while $8.1 \%$ moved down, Table 4) and a slight shift to the left for controls (8.7\% had risk estimates move from below to above $1 \%$, while $10.4 \%$ moved down, Table 4 ).

\section{Discussion}

Circulating AMH and testosterone moderately increased the discriminatory accuracy of the Gail breast cancer risk prediction model among women ages $35-50$ in our study of 1762 invasive cases and 1890 matched controls. Discriminatory accuracy improved with the addition of either $\mathrm{AMH}$ or testosterone, though the improvement was only statistically significant for AMH. In the model including both biomarkers, we observed an AUC increase from 55.3 to 58.1 (relative increase of 5.1\%). Overall, inclusion of biomarkers tended to moderately increase 5-year risk estimates for cases and reduce estimates for controls.

The increase in AUC resulting from the addition of biomarkers was slightly higher in analyses limited to women without a family history of breast cancer than that observed in analyses including all women. This is of interest because the majority of breast cancers occur among women without a family history. Further, women without a family history are the group in which improvements in risk prediction could have the most impact, since it is already recommended that women with a family history start screening early (https://www.uspreventi veservicestaskforce.org/Page/Document/UpdateSummar yFinal/breast-cancer-screening1).

While risk prediction models applicable to younger women would be valuable for screening and preventive treatment decision-making, less work has focused on this group of women as compared to older women [52-54]. To our knowledge, risk prediction estimation has been assessed for premenopausal women from 

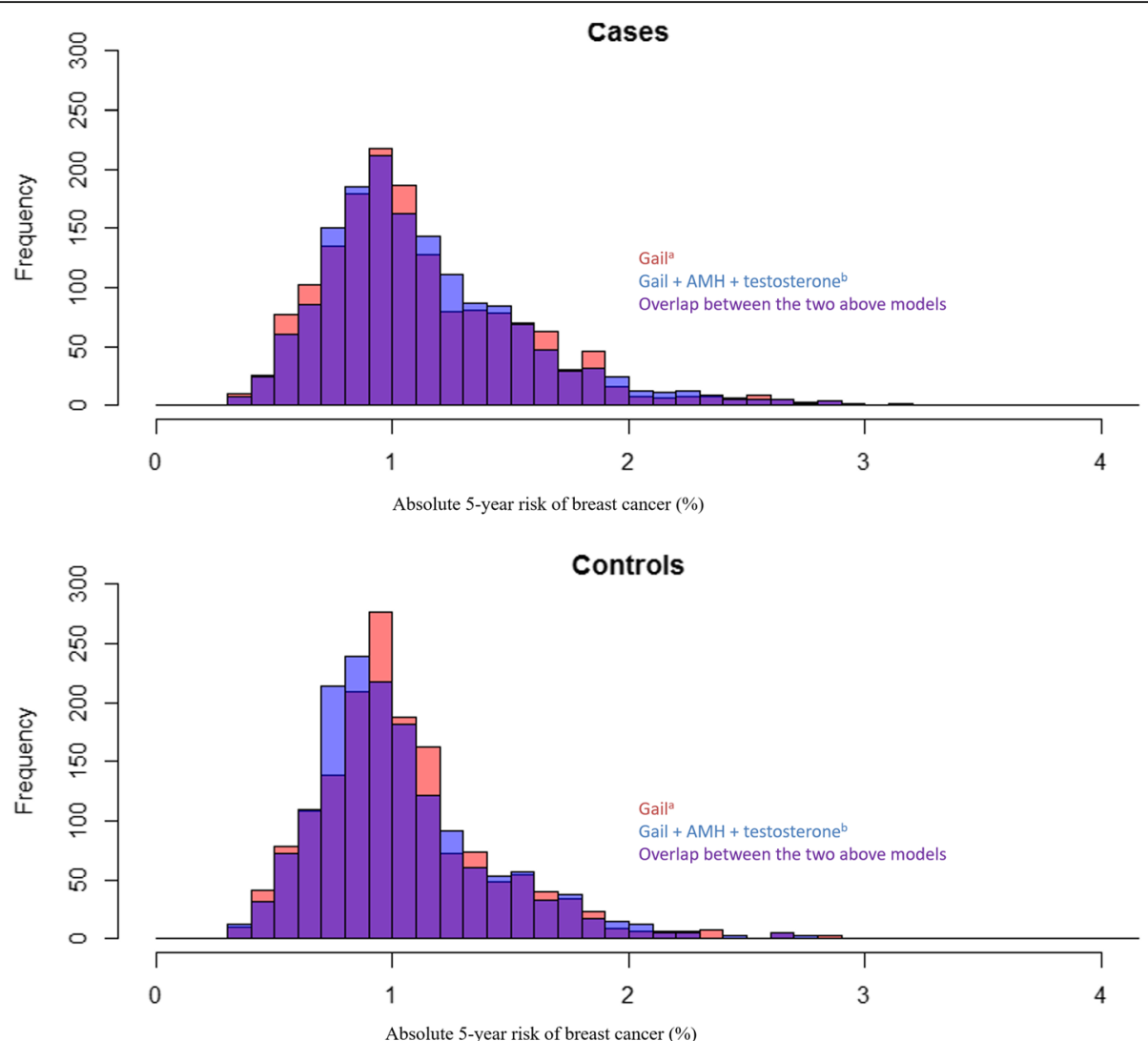

Fig. 2 Reclassification of absolute 5-year risk of breast cancer with the addition of AMH and testosterone to the Gail model

the general population in six studies [55-60]. Most of these assessed or modified the Gail model, but some had extensive missing data for Gail model variables $[55,57]$ or did not assess discriminatory accuracy [57]. Others developed new models for which validation has not yet been attempted in independent studies $[55,60]$. Testosterone was added to the Gail model in one study that included premenopausal women [56]. In this study of 430 cases/684 controls, the addition of hormones, including testosterone, to the Gail model did not

Table 4 Absolute risk reclassification upon adding $\mathrm{AMH}$ and testosterone to the Gail model

\begin{tabular}{|c|c|c|c|c|c|}
\hline & & \multicolumn{2}{|c|}{$\begin{array}{l}\text { Gail + AMH + } \\
\text { testosterone } \\
\text { 5-year risk }\end{array}$} & \multirow[t]{2}{*}{$\begin{array}{l}\text { Moved } \\
\text { up (\%) }\end{array}$} & \multirow[t]{2}{*}{$\begin{array}{l}\text { Moved } \\
\text { down (\%) }\end{array}$} \\
\hline \multicolumn{2}{|c|}{ Reclassification in cases } & $<1 \%$ & $\geq 1 \%$ & & \\
\hline \multirow[t]{3}{*}{ Gail 5-year risk } & $<1 \%$ & 588 & 163 & & \\
\hline & $\geq 1 \%$ & 143 & 868 & & \\
\hline & & & & $9.3 \%$ & $8.1 \%$ \\
\hline \multicolumn{2}{|c|}{ Reclassification in controls } & $<1 \%$ & $\geq 1 \%$ & & \\
\hline \multirow[t]{3}{*}{ Gail 5-year risk } & $<1 \%$ & 708 & 165 & & \\
\hline & $\geq 1 \%$ & 196 & 821 & & \\
\hline & & & & $8.7 \%$ & $10.4 \%$ \\
\hline
\end{tabular}

result in any change in the AUC for premenopausal women [56]. Unlike this study, the increase in AUC that we observed with the addition of testosterone is in agreement with the premenopausal testosterone-breast cancer risk association that has been consistently observed [25-30]. AMH has not been included in breast cancer risk prediction models previously.

Some studies, though not all [61, 62], have reported correlations of BMI with testosterone and AMH in premenopausal women [39, 63, 64]. These correlations have generally been weak, including in our study (Spearman partial correlations with BMI among controls, adjusted for cohort and age, were 0.06 for testosterone, and 0.07 for AMH). This suggests that including BMI in the model, though it would be easier than including biomarkers because BMI does not require a blood draw, would not capture the impact of $\mathrm{AMH}$ and testosterone on breast cancer risk.

The AUC increases with the addition of $\mathrm{AMH}$, and testosterone were greater for ER-positive than ER-negative tumors, as expected since AMH was more strongly associated with risk of ER-positive than ER-negative tumors in our study [24]. Though AMH and estrogen concentrations are not strongly correlated in premenopausal women $[39,64]$, AMH is strongly associated with age at 
menopause, at which time estrogen exposure decreases. This association may explain the greater improvement in prediction of estrogen-sensitive tumors than ER-negative tumors with the inclusion of $\mathrm{AMH}$ in the Gail model.

Several other risk factors have been proposed for inclusion in the Gail model to improve discriminatory accuracy, with varying applicability to premenopausal women. Mammographic density has been shown to increase the discriminatory accuracy of the Gail model in several studies [51, 55, 65, 66], but density is not available yet to women deciding when to begin screening. Endogenous hormones other than AMH and testosterone, such as estrogen, progesterone, and prolactin, fluctuate during the menstrual cycle and/or are not consistently associated with risk in premenopausal women [31, 67]. Common, low-penetrance genetic risk factors may also have utility for risk prediction in younger women. Single nucleotide polymorphisms (SNPs), and their combined risk scores (ranging from 6 to 77 SNPs across studies), have increased Gail model AUCs (AUC increases of 0.6-7.0) in most studies [54, 59, 68-75], including among younger women [59]. Inclusion of a 77-SNP score increased the AUC from 0.64 to 0.66 among women $<50$ years of age [59], an increase comparable to that observed with the addition of AMH and testosterone. Because most genetic variants that are associated with breast cancer risk are not in hormone-related genes, they are likely to contribute to risk prediction independently of AMH and testosterone. Thus, models including both genetic variants and hormone biomarkers as a panel may perform better than models including only one type of marker.

We could not directly assess the calibration of the model including biomarkers because AMH and testosterone were measured only in matched case-control sets; thus, the expected number of cases in the full cohorts using the model including biomarkers could not be estimated [76]. Another method to indirectly assess calibration is inverse probability weighting [77], which uses the probability of being selected into the nested case-control study as a weighting factor to estimate the expected number of cases in the cohort. However, closely matched nested case-control studies, as in this consortium, yield high selection probabilities for a substantial proportion of controls because the risk sets from which controls are selected can be very small. For example, for the 496 controls in the NYUWHS, we would expect an average selection probability of $\sim 10 \%$ (5600 cohort participants were between the ages of 35 and 50 at enrollment), but the average probability was $35 \%$. The controls in this study provided insufficient information about the full cohort, precluding the assessment of calibration [76].
Our study included past users of oral contraceptives (>65\%) [24], but not current users because AMH levels go down during oral contraceptive use [62, 78, 79]. Thus, our results only apply to women not on oral contraceptives.

In addition to the large size of our study, its major strength is the prospective design. Samples collected prior to diagnosis are valuable for measuring biomarkers that can be affected by the diagnosis and/or treatment of breast cancer. Another strength is that detailed epidemiological data on breast cancer risk factors were collected from all cohorts.

\section{Conclusions}

In conclusion, we observed moderate increases in the discriminatory accuracy of the Gail model 2 for women aged 35-50 with the addition of AMH and testosterone. Combining these markers with others (e.g., SNPs) may improve risk prediction models, though the improvement in discriminatory accuracy will remain limited until new markers with stronger associations with breast cancer risk are identified [80, 81].

\section{Additional file}

\begin{abstract}
Additional file 1: Table S1. Breast cancer incidence and competing mortality rates used for each cohort to estimate absolute risk. Table S2. Descriptive characteristics of invasive + in situ cases and matched controls. Table S3. Descriptive characteristics of invasive breast cancer cases and matched controls, by cohort. Table S4. Descriptive characteristics of invasive plus in situ breast cancer cases and matched controls, by cohort. Table S5. Random-effects meta-analysis relative risk estimates, invasive and in situ. Figure S1. Cohort-specific and random-effects meta-analysis relative risk estimates for Gail model variables, $\mathrm{AMH}$ and testosterone (invasive cases only). Figure S2. Cohort-specific and random-effects meta-analysis relative risk estimates for Gail model variables, $\mathrm{AMH}$ and testosterone, invasive and in situ. Figure S3. Relative risk estimates by age group, invasive cases only. Figure S4. AUCs by cohort 95\% confidence intervals, invasive and in situ. (DOCX $254 \mathrm{~kb})$
\end{abstract}

\section{Abbreviations}

AMH: Anti-Müllerian hormone; AUC: Area under the receiver operating characteristic curve; BCRAT: Breast Cancer Risk Assessment Tool; BGS: The Generations Study; BMI: Body mass index; CSB: Columbia, MO Serum Bank; CV: Coefficient of variation; ER: Estrogen receptor; LDV: Lowest detected value; NHS: Nurses' Health Study; NSMSC: Northern Sweden Mammary Screening Cohort; NYUWHS: New York University Women's Health Study; ORDET: Hormones and Diet in the Etiology of Breast Cancer; RR: Relative risk

\section{Acknowledgements}

We thank the $\mathrm{NCl}$ Cohort Consortium. CLUE authors would like to thank the State of Maryland, the Maryland Cigarette Restitution Fund, and the National Program of Cancer Registries of the Centers for Disease Control and Prevention for the funds that helped support the collection and availability of the cancer registry data. The CLUE authors would also like to thank the CLUE participants and staff at the George W. Comstock Center for Public Health Research and Prevention. NHS authors thank the participants and staff of the $\mathrm{NHS}$ and NHSII for their valuable contributions as well as the following state cancer registries for their help: $A L, A Z, A R, C A, C O, C T, D E, F L, G A, I D, I L, I N, I A$, $\mathrm{KY}, \mathrm{LA}, \mathrm{ME}, \mathrm{MD}, \mathrm{MA}, \mathrm{MI}, \mathrm{NE}, \mathrm{NH}, \mathrm{NJ}, \mathrm{NY}, \mathrm{NC}, \mathrm{ND}, \mathrm{OH}, \mathrm{OK}, \mathrm{OR}, \mathrm{PA}, \mathrm{RI}, \mathrm{SC}, \mathrm{TN}$, TX, 
VA, WA, WY. The authors assume full responsibility for analyses and interpretation of these data.

\section{Funding}

This work was supported by grant NIH R01 CA178949. Support for the individual cohorts included:

The Generations Study (BGS): This work was supported by Breast Cancer Now and The Institute of Cancer Research. We acknowledge NHS funding to the Royal Marsden and The Institute of Cancer Research NIHR Biomedical Research Centre. Columbia, MO Serum Bank (CSB): This research was supported by the Intramural Research Program of the $\mathrm{NIH}$, National Cancer Institute and the Department of Defense Breast Cancer Research Program (BC062367). Guernsey cohort (Guernsey): Cancer Research UK C570/A16491. Availability of data and materials: Data access policies for the Guernsey study are available on the Cancer Epidemiology Unit website at https://www.ceu. ox.ac.uk/policies2. Nurses' Health Study (NHS): NCI UM1 CA186107; R01 CA49449. Nurses' Health Study II (NHSII): NCI UM1 CA176726; R01 CA67262. New York University Women's Health Study (NYUWHS): NIH R01 CA098661, UM1 CA182934 and center grants P30 CA016087 and P30 ES000260. Sister Study: This research was supported in part by the Intramural Research Program of the $\mathrm{NIH}$, National Institute of Environmental Health Sciences (Z01-ES044005) to D.P. Sandler and the Avon Foundation (02-2012-085) to H.B. Nichols and D.P. Sandler.

\section{Availability of data and materials}

All data relevant to this report are included in this published article and its supplementary information files. The datasets analyzed during the current study are not publicly available due to protection of participant privacy and confidentiality but are available in anonymized form from the corresponding author on reasonable request.

\section{Authors' contributions}

TVC, WG, KLK, AZJ, and ML were involved in the study conception and design. TVC, WG, KLK, YA, CA, LAB, FD, JFD, AHE, RTF, GH, SHE, JHB, TJK, VK, HBN, DPS, MJS, PMS, MS, AJS, KV, AZJ, and ML acquired the data and participated in the interpretation and analysis of data. TVC, WG, KLK, YA, AZJ, and ML drafted the manuscript. TVC, WG, KLK, YA, CA, LAB, FD, JFD, AHE, RTF, GH, SHE, JHB, TJK, VK, HBN, DPS, MJS, PMS, MS, AJS, KV, AZJ, and ML revised the manuscript critically for intellectual content. All authors approve the final manuscript as submitted.

\section{Ethics approval and consent to participate}

Each cohort was approved by its institutional ethical review board.

\section{Consent for publication}

Not applicable.

\section{Competing interests}

The authors declare that they have no competing interests.

\section{Publisher's Note}

Springer Nature remains neutral with regard to jurisdictional claims in published maps and institutional affiliations.

\section{Author details}

${ }^{1}$ Department of Population Health, New York University School of Medicine, 650 First Avenue, New York, NY 10016, USA. '2Department of Pathology, New York University School of Medicine, New York, NY, USA. ${ }^{3}$ Perlmutter Cancer Center, New York University School of Medicine, New York, NY, USA. ${ }^{4}$ Epidemiology and Prevention Unit, Fondazione IRCCS - Istituto Nazionale dei Tumori, Milan, Italy. ${ }^{5}$ Division of Cancer Epidemiology and Genetics, National Cancer Institute, National Institutes of Health, Bethesda, MD, USA. ${ }^{6}$ Department of Epidemiology and Public Health, University of Maryland School of Medicine, Baltimore, MD, USA. ${ }^{7}$ Department of Epidemiology, Harvard T.H. Chan School of Public Health, and Channing Division of Network Medicine, Brigham and Women's Hospital, Harvard Medical School, Boston, MA, USA. ${ }^{8}$ Department of Biostatistics and Epidemiology, School of Public Health and Health Sciences, University of Massachusetts, Amherst, MA USA. ${ }^{9}$ Department of Biobank Research, Public Health and Clinical Medicine, Umeå University, Umeå, Sweden. ${ }^{10}$ Department of Epidemiology, Johns Hopkins Bloomberg School of Public Health, Baltimore, MD, USA. ${ }^{11}$ Sidney
Kimmel Cancer Center, Johns Hopkins School of Medicine, Baltimore, MD, USA. ${ }^{12}$ Cancer Epidemiology Unit, Nuffield Department of Population Health, University of Oxford, Oxford, UK. ${ }^{13}$ Department of Epidemiology, University of North Carolina, Chapel Hill, NC, USA. ${ }^{14}$ Epidemiology Branch, National Institute of Environmental Health Sciences, Research Triangle Park, NC, USA. ${ }^{15}$ Division of Genetics and Epidemiology, The Institute of Cancer Research, London, UK. ${ }^{16}$ Division of Breast Cancer Research, The Institute of Cancer Research, London, UK. ${ }^{17}$ Department of Pathology, Harvard Medical School, Boston, MA, USA. ${ }^{18}$ Department of Surgery, Umeå University Hospital, Umeå, Sweden.

Received: 20 November 2018 Accepted: 5 March 2019

Published online: 19 March 2019

\section{References}

1. U.S. Preventive Services Task Force. Screening for breast cancer: U.S. Preventive Services Task Force recommendation statement. Ann Intern Med. 2009;151(10):716-26.

2. Smith R, Cokkinides V, Brooks D, Saslow D, Brawley O. Cancer screening in the United States, 2010: a review of current American Cancer Society guidelines and issues in cancer screening. Ca. 2010;60(2):99-119.

3. Hauk L. Practice guidelines: American College of Obstetricians and Gynecologists updates Breast Cancer screening guidelines. Am Fam Physician. 2012;85:654-5.

4. American College of Obstetricians and gynecologists. Practice bulletin no. 122: breast cancer screening. Obstet Gynecol. 2011;118:372-82.

5. Klabunde CN, Ballard-Barbash R. Evaluating population-based screening mammography programs internationally. Semin Breast Dis. 2007;10(2):102-7.

6. Schopper $\mathrm{D}$, de Wolf $\mathrm{C}$. How effective are breast cancer screening programmes by mammography? Review of the current evidence. Eur J Cancer. 2009;45(11): 1916-23.

7. Oeffinger $\mathrm{KC}$, Fontham EH, Etzioni R, et al. Breast cancer screening for women at average risk: 2015 guideline update from the American Cancer Society. JAMA. 2015;314(15):1599-614.

8. Gail MH, Costantino JP, Bryant J, Croyle R, Freedman L, Helzlsouer K, Vogel $\mathrm{V}$. Weighing the risks and benefits of tamoxifen treatment for preventing breast cancer. J Natl Cancer Inst. 1999;91 (21):1829-46.

9. Fisher B, Costantino JP, Wickerham DL, Redmond CK, Kavanah M, Cronin WM, Vogel V, Robidoux A, Dimitrov N, Atkins J, et al. Tamoxifen for prevention of breast cancer: report of the National Surgical Adjuvant Breast and Bowel Project P-1 Study. J Natl Cancer Inst. 1998;90(18):1371-88.

10. Vogel VG, Costantino JP, Wickerham DL, Cronin WM, Cecchini RS, Atkins JN, Bevers TB, Fehrenbacher L, Pajon ER Jr, Wade JL 3rd, et al. Effects of tamoxifen vs raloxifene on the risk of developing invasive breast cancer and other disease outcomes: the NSABP study of tamoxifen and raloxifene (STAR) P-2 trial. JAMA. 2006:295(23):2727-41.

11. Visvanathan $\mathrm{K}$, Chlebowski RT, Hurley P, Col NF, Ropka M, Collyar D, Morrow $\mathrm{M}$, Runowicz C, Pritchard Kl, Hagerty K, et al. American society of clinical oncology clinical practice guideline update on the use of pharmacologic interventions including tamoxifen, raloxifene, and aromatase inhibition for breast cancer risk reduction. J Clin Oncol. 2009;27(19):3235-58.

12. Freedman AN, Graubard BI, Rao SR, McCaskill-Stevens W, Ballard-Barbash R, Gail MH. Estimates of the number of US women who could benefit from tamoxifen for breast cancer chemoprevention. J Natl Cancer Inst. 2003;95(7): 526-32.

13. Visvanathan K, Hurley P, Bantug E, Brown P, Col NF, Cuzick J, Davidson NE, DeCensi A, Fabian C, Ford L, et al. Use of pharmacologic interventions for breast cancer risk reduction: American Society of Clinical Oncology clinical practice guideline. J Clin Oncol. 2013;31(23):2942-62.

14. Costantino JP, Gail MH, Pee D, Anderson S, Redmond CK, Benichou J, Wieand HS. Validation studies for models projecting the risk of invasive and total breast cancer incidence. J Natl Cancer Inst. 1999;91:1541-8.

15. Rockhill B, Spiegelman D, Byrne C, Hunter DJ, Colditz GA. Validation of the Gail et al. model of breast cancer risk prediction and implications for chemoprevention. J Natl Cancer Inst. 2001;93(5):358-66.

16. Chlebowski RT, Anderson GL, Lane DS, Aragaki AK, Rohan T, Yasmeen S, Sarto G, Rosenberg CA, Hubbell FA, Investigators FtWsHI. Predicting risk of breast cancer in postmenopausal women by hormone receptor status. J Natl Cancer Inst. 2007;99(22):1695-705.

17. Bondy ML, Vogel VG. Re: validation of the Gail et al. model for predicting individual breast cancer risk. J Natl Cancer Inst. 1994;86(17):1350. 
18. Pankratz VS, Hartmann LC, Degnim AC, Vierkant RA, Ghosh K, Vachon CM, Frost MH, Maloney SD, Reynolds C, Boughey JC. Assessment of the accuracy of the Gail model in women with atypical hyperplasia. J Clin Oncol. 2008; 26(33):5374-9.

19. Pfeiffer RM, Park Y, Kreimer AR, Lacey JV, Pee D, Greenlee RT, Buys SS, Hollenbeck A, Rosner B, Gail MH, et al. Risk prediction for breast, endometrial, and ovarian cancer in White women aged 50 y or older: derivation and validation from population-based cohort studies. PLoS Med. 2013;10(7):e1001492

20. Decarli A, Calza S, Masala G, Specchia C, Palli D, Gail MH. Gail model for prediction of absolute risk of invasive breast cancer: independent evaluation in the Florence-European prospective investigation into Cancer and Nutrition Cohort. J Natl Cancer Inst. 2006:98(23):1686-93.

21. Matsuno RK, Costantino JP, Ziegler RG, Anderson GL, Li H, Pee D, Gail MH. Projecting individualized absolute invasive breast cancer risk in Asian and Pacific Islander American women. J Natl Cancer Inst. 2011;103(12):951-61.

22. Gail MH, Costantino JP, Pee D, Bondy M, Newman L, Selvan M, Anderson GL, Malone KE, Marchbanks PA, McCaskill-Stevens W, et al. Projecting individualized absolute invasive breast cancer risk in African American women. J Natl Cancer Inst. 2007;99(23):1782-92.

23. Schonfeld SJ, Pee D, Greenlee RT, Hartge P, Lacey JV Jr, Park Y, Schatzkin A, Visvanathan K, Pfeiffer RM. Effect of changing breast cancer incidence rates on the calibration of the Gail model. J Clin Oncol. 2010;28(14):2411-7.

24. Ge W, Clendenen TV, Afanasyeva Y, Koenig KL, Agnoli C, Brinton LA, Dorgan JF, Eliassen AH, Falk RT, Hallmans G, et al. Circulating anti-Mullerian hormone and breast cancer risk: a study in ten prospective cohorts. Int J Cancer. 2018; 142(11):2215-26

25. Zeleniuch-Jacquotte A, Afanasyeva Y, Kaaks R, Rinaldi S, Scarmo S, Liu M, Arslan AA, Toniolo P, Shore RE, Koenig KL. Premenopausal serum androgens and breast cancer risk: a nested case-control study. Breast Cancer Res. 2012; 14(1):R32.

26. Micheli A, Muti P, Secreto G, Krogh V, Meneghini E, Venturelli E, Sieri S, Pala $V$, Berrino $F$. Endogenous sex hormones and subsequent breast cancer in premenopausal women. Int J Cancer. 2004;112(2):312-8.

27. Kaaks R, Berrino F, Key T, Rinaldi S, Dossus L, Biessy C, Secreto G, Amiano P, Bingham S, Boeing $\mathrm{H}$, et al. Serum sex steroids in premenopausal women and breast cancer risk within the European Prospective Investigation into Cancer and Nutrition (EPIC). J Natl Cancer Inst. 2005;97(10):755-65.

28. Eliassen AH, Missmer SA, Tworoger SS, Spiegelman D, Barbieri RL, Dowsett $\mathrm{M}$, Hankinson SE. Endogenous steroid hormone concentrations and risk of breast cancer among premenopausal women. J Natl Cancer Inst. 2006; 98(19):1406-15.

29. Dorgan JF, Stanczyk FZ, Kahle LL, Brinton LA. Prospective case-control study of premenopausal serum estradiol and testosterone levels and breast cancer risk. Breast Cancer Res. 2010;12(6):R98.

30. Kaaks R, Tikk K, Sookthai D, Schock H, Johnson T, Tjonneland A, Olsen A, Overvad K, Clavel-Chapelon F, Dossus L, et al. Premenopausal serum sex hormone levels in relation to breast cancer risk, overall and by hormone receptor status - results from the EPIC cohort. Int J Cancer. 2014;134(8): 1947-57.

31. Key T, Appleby P, Barnes I, Reeves G, Endogenous H, Breast Cancer Collaborative G. Endogenous sex hormones and breast cancer in postmenopausal women: reanalysis of nine prospective studies. J Natl Cancer Inst. 2002;94(8):606-16.

32. Zeleniuch-Jacquotte $\mathrm{A}$, Shore RE, Koenig KL, Akhmedkhanov A, Afanasyeva Y, Kato I, Kim MY, Rinaldi S, Kaaks R, Toniolo P. Postmenopausal levels of oestrogen, androgen, and SHBG and breast cancer: long-term results of a prospective study. Br J Cancer. 2004;90(1):153-9.

33. Manjer J, Johansson R, Berglund G, Janzon L, Kaaks R, Agren A, Lenner $P$. Postmenopausal breast cancer risk in relation to sex steroid hormones, prolactin and SHBG (Sweden). Cancer Causes Control. 2003;14(7):599-607.

34. Kaaks R, Rinaldi S, Key TJ, Berrino F, Peeters PH, Biessy C, Dossus L, Lukanova A, Bingham S, Khaw KT, et al. Postmenopausal serum androgens, oestrogens and breast cancer risk: the European prospective investigation into cancer and nutrition. Endocr Relat Cancer. 2005;12(4):1071-82.

35. Baglietto L, Severi G, English DR, Krishnan K, Hopper JL, McLean C, Morris HA, Tilley WD, Giles GG. Circulating steroid hormone levels and risk of breast cancer for postmenopausal women. Cancer Epidemiol Biomarkers Prev. 2010;19(2):492-502.

36. Farhat GN, Cummings SR, Chlebowski RT, Parimi N, Cauley JA, Rohan TE, Huang AJ, Vitolins M, Hubbell FA, Manson JE, et al. Sex hormone levels and risks of estrogen receptor-negative and estrogen receptor-positive breast cancers. J Natl Cancer Inst. 2011;103(7):562-70.

37. Zhang X, Tworoger SS, Eliassen AH, Hankinson SE. Postmenopausal plasma sex hormone levels and breast cancer risk over 20 years of follow-up. Breast Cancer Res Treat. 2013;137(3):883-92.

38. Sieri S, Krogh V, Bolelli G, Abagnato CA, Grioni S, Pala V, Evangelista A, Allemani C, Micheli A, Tagliabue G, et al. Sex hormone levels, breast cancer risk, and cancer receptor status in postmenopausal women: the ORDET cohort. Cancer Epidemiol Biomarkers Prev. 2009;18(1):169-76.

39. Eliassen AH, Zeleniuch-Jacquotte A, Rosner B, Hankinson SE. Plasma antiMullerian hormone concentrations and risk of breast cancer among premenopausal women in the Nurses' Health Studies. Cancer Epidemiol Biomarkers Prev. 2016;25(5):854-60.

40. van Rooij IA, Broekmans FJ, Scheffer GJ, Looman CW, Habbema JD, de Jong FH, Fauser BJ, Themmen AP, te Velde ER. Serum antimullerian hormone levels best reflect the reproductive decline with age in normal women with proven fertility: a longitudinal study. Fertil Steril. 2005;83(4):979-87.

41. Dorgan JF, Spittle CS, Egleston BL, Shaw CM, Kahle LL, Brinton LA. Assay reproducibility and within-person variation of Mullerian inhibiting substance. Fertil Steril. 2010;94(1):301-4.

42. Missmer SA, Spiegelman D, Bertone-Johnson ER, Barbieri RL, Pollak MN, Hankinson SE. Reproducibility of plasma steroid hormones, prolactin, and insulin-like growth factor levels among premenopausal women over a 2- to 3-year period. Cancer Epidemiol Biomarkers Prev. 2006;15(5):972-8.

43. de Kat AC, van der Schouw YT, Eijkemans MJ, Herber-Gast GC, Visser JA, Verschuren WM, Broekmans FJ. Back to the basics of ovarian aging: a population-based study on longitudinal anti-Mullerian hormone decline. BMC Med. 2016;14(1):151.

44. La Marca A, Spada E, Grisendi V, Argento C, Papaleo E, Milani S, Volpe A Normal serum anti-Mullerian hormone levels in the general female population and the relationship with reproductive history. Eur J Obstet Gynecol Reprod Biol. 2012;163(2):180-4.

45. Schoemaker MJ, Folkerd EJ, Jones ME, Rae M, Allen S, Ashworth A, Dowsett M, Swerdlow AJ. Combined effects of endogenous sex hormone levels and mammographic density on postmenopausal breast cancer risk: results from the Breakthrough Generations Study. Br J Cancer. 2014;110(7):1898-907.

46. Thomas HV, Key TJ, Allen DS, Moore JW, Dowsett M, Fentiman IS, Wang DY A prospective study of endogenous serum hormone concentrations and breast cancer risk in premenopausal women on the island of Guernsey. $\mathrm{Br}$ J Cancer. 1997;75(7):1075-9.

47. Nichols HB, Baird DD, Stanczyk FZ, Steiner AZ, Troester MA, Whitworth KW, Sandler DP. Anti-Mullerian hormone concentrations in premenopausal women and breast cancer risk. Cancer Prev Research (Phila). 2015;8(6):52834.

48. Fortner RT, Eliassen AH, Spiegelman D, Willett WC, Barbieri RL, Hankinson SE. Premenopausal endogenous steroid hormones and breast cancer risk: results from the Nurses' Health Study II. Breast Cancer Res. 2013;15(2):R19. doi:10.1186/bcr3394.

49. Bruzzi P, Green SB, Byar DP, Brinton LA, Schairer C. Estimating the population attributable risk for multiple risk factors using case-control data. Am J Epidemiol. 1985;122(5):904-14.

50. USA: National Center for Health Statistics, Centers for Disease Control and Prevention. https://www.cdc.gov/nchs/data_access/cmf.htm. Accessed 17 July 2018.

51. Chen J, Pee D, Ayyagari R, Graubard B, Schairer C, Byrne C, Benichou J, Gail MH. Projecting absolute invasive breast cancer risk in white women with a model that includes mammographic density. J Natl Cancer Inst. 2006;98(17):1215-26.

52. Anothaisintawee T, Teerawattananon Y, Wiratkapun C, Kasamesup V, Thakkinstian A. Risk prediction models of breast cancer: a systematic review of model performances. Breast Cancer Res Treat. 2012;133(1):1-10.

53. Tworoger SS, Zhang X, Eliassen AH, Qian J, Colditz GA, Willett WC, Rosner $B A$, Kraft $P$, Hankinson SE. Inclusion of endogenous hormone levels in risk prediction models of postmenopausal breast cancer. J Clin Oncol. 2014; 32(28):3111-7.

54. Wacholder S, Hartge P, Prentice R, Garcia-Closas M, Feigelson HS, Diver WR, Thun MJ, Cox DG, Hankinson SE, Kraft P, et al. Performance of common genetic variants in breast-cancer risk models. N Engl J Med. 2010;362(11): 986-93.

55. Barlow WE, White E, Ballard-Barbash R, Vacek PM, Titus-Ernstoff L, Carney PA, Tice JA, Buist DS, Geller BM, Rosenberg R, et al. Prospective breast cancer 
risk prediction model for women undergoing screening mammography J Natl Cancer Inst. 2006;98(17):1204-14.

56. Hüsing A, Fortner RT, Kühn T, Overvad K, Tjønneland A, Olsen A, BoutronRuault M-C, Severi G, Fournier A, Boeing H, et al. Added value of serum hormone measurements in risk prediction models for breast cancer for women not using exogenous hormones: results from the EPIC cohort. Clin Cancer Res. 2017;

57. Mackarem G, Roche CA, Hughes KS. The effectiveness of the Gail model in estimating risk for development of breast cancer in women under 40 years of age. Breast J. 2001;7(1):34-9.

58. Dartois L, Gauthier É, Heitzmann J, Baglietto L, Michiels S, Mesrine S, Boutron-Ruault M-C, Delaloge S, Ragusa S, Clavel-Chapelon F, et al. A comparison between different prediction models for invasive breast cancer occurrence in the French E3N cohort. Breast Cancer Res Treat. 2015;150(2):415-26.

59. Dite GS, MacInnis RJ, Bickerstaffe A, Dowty JG, Allman R, Apicella C, Milne RL, Tsimiklis H, Phillips KA, Giles GG, et al. Breast cancer risk prediction using clinical models and 77 independent risk-associated SNPs for women aged under 50 years: Australian Breast Cancer Family Registry. Cancer Epidemiol Biomarkers Prev. 2016;25(2):359-65.

60. Ueda K, Tsukuma H, Tanaka H, Ajiki W, Oshima A. Estimation of individualized probabilities of developing breast cancer for Japanese women. Breast Cancer. 2003;10(1):54-62.

61. Lukanova A, Lundin E, Zeleniuch-Jacquotte A, Muti P, Mure A, Rinaldi S, Dossus L, Micheli A, Arslan A, Lenner P, et al. Body mass index, circulating levels of sex-steroid hormones, IGF-I and IGF-binding protein-3: a crosssectional study in healthy women. Eur J Endocrinol. 2004;150(2):161-71.

62. Shaw CM, Stanczyk FZ, Egleston BL, Kahle LL, Spittle CS, Godwin AK, Brinton $L A$, Dorgan JF. Serum antimullerian hormone in healthy premenopausal women. Fertil Steril. 2011;95(8):2718-21.

63. Nichols HB, Baird DD, Stanczyk FZ, Steiner AZ, Troester MA, Whitworth KW, Sandler DP. Anti-Mullerian hormone concentrations in premenopausal women and breast cancer risk. Cancer Prev Res (Phila). 2015;8(6):528-34.

64. Dorgan JF, Stanczyk FZ, Egleston BL, Kahle LL, Shaw CM, Spittle CS, Godwin AK, Brinton LA. Prospective case-control study of serum mullerian inhibiting substance and breast cancer risk. J Natl Cancer Inst. 2009;101(21):1501-9.

65. Tice JA, Cummings SR, Ziv E, Kerlikowske K. Mammographic breast density and the Gail model for breast cancer risk prediction in a screening population. Breast Cancer Res Treat. 2005;94(2):115-22.

66. Tice JA, Cummings SR, Smith-Bindman R, Ichikawa L, Barlow WE, Kerlikowske K. Using clinical factors and mammographic breast density to estimate breast cancer risk: development and validation of a new predictive model. Ann Intern Med. 2008;148(5):337-47.

67. Endogenous H, Breast Cancer Collaborative G, Key TJ, Appleby PN, Reeves GK, Travis RC, Alberg AJ, Barricarte A, Berrino F, Krogh V, et al. Sex hormones and risk of breast cancer in premenopausal women: a collaborative reanalysis of individual participant data from seven prospective studies. Lancet Oncol. 2013;14(10):1009-19.

68. Mealiffe ME, Stokowski RP, Rhees BK, Prentice RL, Pettinger M, Hinds DA. Assessment of clinical validity of a breast cancer risk model combining genetic and clinical information. J Natl Cancer Inst. 2010;102(21):1618-27.

69. Gail MH. Discriminatory accuracy from single-nucleotide polymorphisms in models to predict breast cancer risk. J Natl Cancer Inst. 2008;100(14):1037-41.

70. Dite GS, Mahmoodi M, Bickerstaffe A, Hammet F, Macinnis RJ, Tsimiklis H, Dowty JG, Apicella C, Phillips KA, Giles GG, et al. Using SNP genotypes to improve the discrimination of a simple breast cancer risk prediction model. Breast Cancer Res Treat. 2013;139(3):887-96.

71. Allman R, Dite GS, Hopper JL, Gordon O, Starlard-Davenport A, Chlebowski $R$, Kooperberg C. SNPs and breast cancer risk prediction for African American and Hispanic women. Breast Cancer Res Treat. 2015;154(3):583-9.

72. Darabi H, Czene K, Zhao W, Liu J, Hall P, Humphreys K. Breast cancer risk prediction and individualised screening based on common genetic variation and breast density measurement. Breast Cancer Res. 2012;14(1):R25.

73. Lee CP, Choi H, Soo KC, Tan MH, Chay WY, Chia KS, Liu J, Li J, Hartman M. Mammographic breast density and common genetic variants in breast cancer risk prediction. PLoS One. 2015;10(9):e0136650.

74. McCarthy AM, Armstrong K, Handorf E, Boghossian L, Jones M, Chen J, Demeter MB, McGuire E, Conant EF, Domchek SM. Incremental impact of breast cancer SNP panel on risk classification in a screening population of white and African American women. Breast Cancer Res Treat. 2013;138(3): 889-98.
75. Husing A, Canzian F, Beckmann L, Garcia-Closas M, Diver WR, Thun MJ, Berg CD, Hoover RN, Ziegler RG, Figueroa JD, et al. Prediction of breast cancer risk by genetic risk factors, overall and by hormone receptor status. J Med Genet. 2012;49(9):601-8.

76. Ganna A, Reilly M, de Faire U, Pedersen N, Magnusson P, Ingelsson E. Risk prediction measures for case-cohort and nested case-control designs: an application to cardiovascular disease. Am J Epidemiol. 2012;175(7):715-24.

77. Samuelsen S. A pseudolikelihood approach to analysis of nested case-control studies. Biometrika. 1997;84(2):379-94.

78. Jung S, Allen N, Arslan AA, Baglietto L, Brinton LA, Egleston BL, Falk R, Fortner RT, Helzlsouer KJ, Idahl A, et al. Demographic, lifestyle, and other factors in relation to anti-Müllerian hormone levels in mostly late premenopausal women. Fertil Steril. 2017;107(4):1012-1022.e1012.

79. Birch Petersen K, Hvidman HW, Forman JL, Pinborg A, Larsen EC, Macklon $K T$, Sylvest R, Andersen AN. Ovarian reserve assessment in users of oral contraception seeking fertility advice on their reproductive lifespan. Hum Reprod. 2015:30(10):2364-75.

80. Gail MH. Twenty-five years of breast cancer risk models and their applications. J Natl Cancer Inst. 2015;107(5):djv042.

81. Garcia-Closas M, Gunsoy NB, Chatterjee N. Combined associations of genetic and environmental risk factors: implications for prevention of breast cancer. J Natl Cancer Inst. 2014;106(11):dju305.
Ready to submit your research? Choose BMC and benefit from:

- fast, convenient online submission

- thorough peer review by experienced researchers in your field

- rapid publication on acceptance

- support for research data, including large and complex data types

- gold Open Access which fosters wider collaboration and increased citations

- maximum visibility for your research: over $100 \mathrm{M}$ website views per year

At BMC, research is always in progress.

Learn more biomedcentral.com/submissions 